through the material of some bodies as well as through the ether within those bodies.

A subject of this kind has no end. No matter where we stop, it is bound to be left unfinished.

ON SCIENCE TEACHING. II.

By C. R. MANN.

Ryerson Physical Laboratory, University of Chicago.

A great deal is being said and written nowadays about correlating subjects in the school curriculum. And by this is generally meant the teaching in one department of subject matter usually classed as belonging to another department. Thus we are said to correlate mathematics and physics by teaching mathematical principles in connection with physical experiments; or, as it is sometimes stated, by rendering mathematics concrete by basing its theorems on physical phenomena.

Useful as such correlation is, it must be clear to the thoughtful teacher that it lacks an element of reality-that it is at best but an external makeshift, guided by no fundamental principle, and based on nothing that is vital to both subjects. Yet it indicates progress, and the presence of a vague sense that there must be some grounds or principles common to the different branches of instruction. Let us see if such a relating idea cannot be found; for evidently there can be no real correlation among subjects unless it is based on something that they all possess-some unifying, central, basic principle.

In order not to make the discussion too broad, this paper will be devoted to a discussion of the sciences only, leaving the more general question for later consideration. What, then, we may ask, is the unifying idea among the sciences? What is it that they all have in common, and without which they would not be sciences?

The answer is not hard to find. It may, perhaps, be made most forceful by considering first why there was no science during the Middle Ages, and what was needed to bring science into being. No one to whom this question is put will hesitate an instant to reply that science began to blossom and bear fruit when men began to use the scientific method of investigation. 
Therefore, is it not true, that it is this scientific method of investigation which is above all things the center and soul of science? Is it not the one thing which the scierices all have in common, and without which they would not be science?

If this scientific method of thought is the chief characteristic of science, it becomes of interest to try to define it more clearlyto attempt to find out whether all the sciences are equally good exponents of it, and whether they all use it in the same way. A complete discussion of this question is beyond the scope of a brief paper like this, even if it could be given at all. There are, however, some interesting facts which appear from even a brief investigation.

In the first place, it is noteworthy that the various sciences are not equally old. Thus geometry is the oldest; then comes formal astronomy. These two were cultivated by the Ancient Egyptians and Greeks. In the sixteenth century chemistry and physics became sciences. These were followed in the eighteenth by the biological sciences, and, finally, in the nineteenth century, came sociology, claiming place with the rest.

Now, if, as has often been rightly said, the function of science instruction is to train in the scientific method of thought, would the same conception of that method be obtained from a study of each of these sciences? Yet if that method can be staked off into the four steps of observation, induction, deduction and verification, why do we fail to recognize the mental processes in geometry and in sociology as the same? Is geometry wholly deductive, and sociology wholly inductive?

Whatever may have been the method employed in obtaining the axioms of geometry, its present methods seem to be largely deductive, i. e., it is an exemplification of the latter stages of the scientific method. It is also the oldest of the sciences. Sociology, on the other hand, has not reached any axioms, nor yet any working hypotheses as well developed as is that of the conservation of energy in physics. In other words, it is in the earlier stages of the scientific method. It is also the youngest of the sciences. Does not sociology use deduction and verification? Certainly; but, in a general way, its processes illustrate the earlier stages of the method under consideration.

The biological sciences, though vastly more advanced than 
sociology, may be considered to be still engaged in the process of building their general pinciples, while physics and chemistry have reached some of theirs, and are working both inductively and deductively for the attainment of others. From this point of view, then, we might consider that, in a general sort of a way, the older the science; the more it becomes an exemplification of the later stages of the scientific method, while the newer sciences are mainly involved in the earlier stages.

If this point of view be taken, it follows that if we would master this method completely in all its intricacies, we should have to study in detail the processes employed in all the sciences. This method is, then, not so simple an affair as it may at first sight appear to be. And, in fact, the more we try to analyze the two processes which we so glibly call induction and deduction, and to distinguish in detail between them, the more inextricably entangled we find them to be. Follow any argument into detail, and see if you can determine definitely which part of it is wholly inductive, and which deductive-see if you can find portions that are deductive only. In general this is easy to do, just as it is apparent on the surface that the methods of geometry differ in general from those of sociology.

In short, the scientific method, if followed too much into detail, is found to be very complex. It has been rightly called the modern logic, and it is as much more complicated and involved than the logic of Aristotle as the modern life is more complicated and involved than that of the Greeks. Yet there are several very definite things about the scientific method which it is of great value to science teaching to understand, if we are to teach the sciences in a correlated way. These things must be sought in the general scientific attitude, rather than in the detailed processes employed in any particular case; these latter are too complicated to be able to guide us in gencral.

The first of these general characteristics of the scientific attitude is the habit of basing all conclusions on observed facts, not on hearsay, not on authority. Until a child has learned to keep apart in his mind the facts which he has himself observed and those which he has read of or heard of from others, he has not started fairly toward the attainment of the seientific attitude of mind. If we could all learn not to pass along to others as facts 
things learned from authority only, the world would be a far different places to live in. If we could all learn not to form too fixed conclusions from things learned from hearsay only, what an enormous saving of mental effort would result. This is the first great thing which it is the mission of science, as teacher of the young, to impress on mankind. Train them so that they distinguish carefully between the things observed by themselves, and those facts learned from reading or from conversation with others.

It does not follow from this that a student should find out everything for himself; not yet that he should make all the quantitative experiments himself in the laboratory. He usually has a large amount of qualitative personal experience with the subject matter of science, and can generally obtain a large store of personally observed facts in the routine of his daily life, if only he will keep his eyes open. It does, however, imply teaching him to regard as most real the conclusions based on his own observations.

The other important element of the scientific attitude is the maintenance of an unbiased and impartial mind. This is by far the most difficult attaininent; for we have been so trained for centuries to accept things as dogma on authority, and to learn them from books, that it is difficult to develop that freedom of the personal judgment which is so essential, not only in scientific work, but also in all else that we do. Progress is effected through the action of free thinking individuals who form their conclusions by a personal judgment acting in freedom. Anyone who has developed in him such a really free attitude, must also respect the same thing in others. He must be tolerant, as well as individual. Such a free, personal judgment is also the center of self-activity, for who that is not free can be original?

These two things thus seem to be the essentials of the scientific attitude; and, therefore, for correlation, they should be made the chief aims of science instruction. It is after all immaterial whether a boy or a girl knows the lens formula, or can recite from memory Newton's laws of motion, if he has these two mental traits well developed. But it is an interesting: fact that children trained to observe carefully and to reason 
from those observations clearly and in freedom remember both the facts and the conclusions better than if they are taught the conclusions as a matter of authority. Though it may seem paradoxical, it is yet true, that if we make it our aim to teach the facts and principles of science, we fail; but if we have as our sole purpose the development in the children of this scientific attitude, they not only acquire that most valuable possession, but also learn the principles better. Moreover, by the adoption of this aim, the sciences become truly correlated. They then come to stand in the curriculum for a certain definite kind of attainment: not for a smattering familiarity with a few facts and theories of physics, of chemistry, of biology,--all the work of other men's hands than theirs,-but for acquired power, free judgment, greater individuality.

One thing more. The scientific method is but a part of a general process of human action. For everything we do may be analyzed into three distinct steps, or phases. In the first place, and most essential, we form a purpose. Can you conceive of an action without some purpose? Are not the great men, the interesting men, those of mighty purpose? In the second place, we find means for the accomplishment of this purpose. And finally, through the means we carry the purpose into action and produce a result.

Now, the scientific method by itself is but the means, and leads to the result. It has no purpose. It is a mere tool. Yet if it is to be a real part of a human action, it must be used in the service of a strong purpose. In the case of the scientist, the purpose is immanent and powerful, for he is fired with the desire to untavel the mysteries of the universe. But how about a student when confronted with one of our ready-made systems as described in a science text? Suppose he knows nothing of science, what is there to awaken in him a purpose to study the subject? It is often said that we must rotuse interest; but is not interest but the manifestation of a purpose? Should we not rather strive to stir up in the youngster a purpose?

This cannot be done in the case of a young student by telling him of the value he will receive from the work in some future age. It may possibly be done through his curiosity. It is at best a subtle thing, this purpose; yet fundamental. For certain 
it is, that if he has no spontaneous purpose, he has no interest, and no self-activity, and does not develop free judgment,"and the fire won't burn the stick, and the stick won't beat the dog, and the dog won't bite the pig, and the pig won't jump over the stile, and I won't get home tonight."

Have not the science teachers a great field of investigation here? Who can tell how purposes are formed in a child? Who can learn to govern or guide them? Yet are they not the reality on which our success or failure in the last analysis depend?

\section{TROPICAL FRUITS.}

BY MEL T. COOK.

Chief of the Department of Vegetable Pathology of the Cuban Agricultural Experimental Station.

III. Orange.

Probably no tropical fruit is so well known and so universally used throughout the civilized world as the orange. In fact it is one of the oldest of cultivated fruits and one of the first to extend its range from its original home. Probably for this reason has its nativity been in such great doubt. It is now generally believed to be of Indo-Chinese origin, and it has undoubtedly been cultivated in India, China and Japan from very remote time. Wild oranges are now said to be very abundant in northern India. It is supposed to have been carried from Hindustan to southwestern Africa by the Arabs probably before the ninth century, and by that same race it was carried on the tide of the Mohammedan conquest and distributed throughout northern Africa and into Spain. But it was destined to come into Europe from another source, and about the twelfth century was introduced into Italy by the returning Crusaders. There its cultivation gradually increased until about the sixteenth century, when it became very common.

From the Mediterranean region it spread throughout the world wherever the conditions were favorable for its growth and is now cultivated in practically all warm, temperate and tropical countries. It is said that the first English settlers in Florida found many trees growing wild. Undoubtedly the seed had been introduced by the early Spanish explorers and settlers, and then carried from place to place by the Indians. 